\title{
OR-7
}

\section{Microbiological Characterization and Physico-Chemical Properties of Sudanese Honeys}

\author{
Mohammed Y. Musa ${ }^{1}$, Ahmed E. Elfaki ${ }^{1}$ and Seif Eldin. A. Mohammed ${ }^{2, *}$ \\ ${ }^{1}$ Department of Food Science and Technology, Faculty of Agricultural Studies, University of Sudan; ${ }^{2}$ National Centre \\ for Research, Environment and Natural Resources Research Institute, P. O. Box 6096 - Khartoum, Sudan; \\ E-mail: seifo169@yahoo.com
}

Honey is not always a safe product and in some instances it is spoiled by the growth of micro-organisms. In this study Sudanese honey brands were investigated for the presence/absence of pathogenic and non pathogenic micro-organisms as well as the physic-chemical properties of honey. The aim of the study was to characterize honey on biological and physic-chemical basis. Several microbiological tests and the AOAC methods were employed. The results of microbiological tests were negative for Salmonella spp., Escherichia coli, and total coliforms ( $\mathrm{mpn} / \mathrm{ml}$ ). Few honey brands contained Clostridium botulinum, Staphylococcus aureus, yeasts and moulds. The maximum total viable bacteria count was $>6000 \mathrm{cfu} / \mathrm{ml}$. The results of the physical properties of the tested honey were as follows: $\mathrm{pH} 3.6$, specific gravity 1.2 , viscosity 120.7 Poise, and refractive index 1.4. For the chemical composition were: moisture 18.2 , acidity $54.2(\mathrm{meq} / \mathrm{kg})$, total sugars $70.5 \%$, fructose $32.1 \%$, glucose $32.8 \%$, and sucrose $5.5 \%$. These results suggest the needs for improved methods for honey collection, processing and safety handling.

Keywords: Honey composition, Clostridium botulinum, Staphylococcus aureus. 